\title{
Endangered: Wildlife on the Brink of Extinction
}

By George C. McGavin. 2006. Firefly Books Ltd. 192 pages. U.S. \$35.00 Cloth

An ecologist could not help but be drawn to a book with the title Endangered. Wildlife on the brink of Extinction. seeking an update on the current state of the world's species at risk. Unfortunately McGavin's book does not provide a succinct analysis of current status, the impacts we should be most concerned about, geographic localities of concern and the likely future trends. Rather this coffee table book provides a piecemeal of "information bites" for fifty animal groups ranging from dogs and cats to salmon and songbirds.

The lengthy (50 of 192 pages) two chapter introduction on the "Nature of Extinction" and "The Sixth Extinction" could be a grade nine biology course covering the basics of evolution and human development from our hunter-gather roots, through our agrarian and industrial revolutions to an assessment of supply and demand harvesting of nature. Instead of a discussion of the ecological implications of the loss of species to ecosystem integrity, extinction is considered more in terms of the extent of human mourning and the likely curiosity of future generations about species that once existed.

The "Lost and the Last" chapter constitutes the central text starting with Monotremes and Marsupials. Typical treatment of species groups include general statements such as: "Platypus eggs are eaten by introduced red foxes and rats as well as by native predators such as lizards. Many echidna eggs suffer the same fate." This text provides no meaningful information on the status of even these most unique of creatures for which clear trends must surely be known. No consistent format is used to cover each animal group, for example within the sub-section Insectivores Insectivora the subtitles used could have been chosen at random: Sense of Smell; Desmans in Danger; Desert Moles; Rare and Restricted; and Solendon Capture. Often the information presented begs the question; What has this to do with wildlife on the brink of extinction? If general ecological information is to be presented it would have been better in a text box or sidebar as a special case study.
Much more information could have been conveyed by following a consistent format for each animal group with sub-headings that allowed the reader to move from one group to another building an understanding of the most threatened species, the number of species threatened within each group, the ecological implications of species loss, the key causes of species decline, likely future trends and actions required to reverse negative trends. Summary graphs, tables or pictorial representations are virtually absent, yet they too could have been used to convey large amounts of information in a simple repeatable format for each species group.

The most impressive aspect of Endangered is surely the figures but, while there are captions, the text makes no direct reference to the figures and text and figures are often unrelated. In the Prosimians group the text states: "The strangest prosimian is surely the aye-aye. Its wide eyes, pointed ears and thin bony fingers lend it a goblin-like appearance". No picture of the aye-aye is included, but pictures of the sifaka and loris are included with no information on their status.

There is considerable variability in the treatment of each species group with some written in a more authoritative style, Bats Chiroptera is one example where there is a logical organization of sub-sections and more information on extinction. Variability is also seen in how comprehensively each species group is covered and this appears unrelated to the extent of information likely available. For example, the monkeys species group includes less than one page of text while the amphibians group has four pages of text.

In summary, Extinction provides an enormous amount of anecdotal information that is interesting to read, but which is likely forgotten soon after having read it. The book leaves the reader with a sense of disaster for all creatures as a result of human activity (which may or may not be far off the truth) and attempts to deal with all the ills of humankind from switching off light bulbs to buying local produce. Unfortunately readers that might be inclined to read Endangered will likely come away knowing little more than they started with.

BRENT TEGLER

North-South Environmental Inc., 35 Crawford Crescent, Unit U5, P.O. Box 518, Campbellville, Ontario LOP 1B0 Canada

\section{MiscellaneOUS}

\section{The Reluctant Mr. Darwin: An Intimate Portrait of Charles Darwin and the Making of His Theory of Evolution}

By David Quammen. 2006. Atlas Books/ W. W. Norton \& Company, New York. 304 pages. \$30.00 Cloth.

As naturalists, we never cease to be amazed by the myriad wonderful life forms in nature, be it the flowering plants that suddenly appear following snowmelt, the wide variety of birds that return north every spring, or the colourful mushrooms found each fall in our forests. However, the source of this very diversity may easily be perplexing: why are there so many species and how did they originate? The theory of evolution has gone a long way towards explaining these and related questions by means of a wealth of empirical and theoretical studies. 